\title{
A new spatial orientation memory test: Evaluation in patients with mild Alzheimer's disease and in patients with operated and unoperated mesial temporal lobe epilepsy
}

\author{
Lisiane Tuon* \\ Mirna Portuguez ${ }^{* \star}$ \\ Iván Izquierdo** \\ Jaderson Costa da Costa** \\ * Universidade do Extremo Sul Catarinense \\ (UESC), Criciúma, SC, Brasil \\ ** Instituto de Pesquisas Biomédicas and \\ Centro de Memoria, Pontificia Universidade \\ Católica de Rio Grande do Sul (PUCRS)
}

BRASIL

\begin{abstract}
Background and objectives: Spatial orientation and spatial learning depend on the medial temporal lobe. A new test of spatial memory in humans is described, and applied to patients with Alzheimer's disease (AD), with presumable damage of that region, and to patients with unilateral mesial temporal sclerosis (MTS) submitted or not to treatment by selective surgical amygdala-hippocampectomy (SAH).

Methods: Subjects were asked to go to each of four objects hanging from the wall of a room: a cylinder, a square, a ball and a triangle (trial 1). In trial 2 they repeated this blindfolded; all figures except the cylinder were removed; once the subjects reached the cylinder they had to say what figures should be at the left, right and back. In trial 3, all figures were withdrawn and the subjects, again blindfolded, were instructed first to go to the front, right, left and back, and then to go to the former positions occupied by the cylinder, the ball, the square and the triangle.

Results: Experiment 1 studied 10 patients with mild AD and 10 controls matched by age, gender and schooling. Performance was $46 \%$ lower in AD patients relative to controls ( $\mathrm{p}<$ 0.001). Experiment 2 studied 23 patients with MTS, 20 patients submitted to SAH, and 23 healthy volunteers with similar levels of age, gender and schooling. No differences in performance among these three groups were observed.

Conclusions: The test distinguished performance deficits of AD patients relative to controls, but not among MTS and STH patients and controls.
\end{abstract}




\section{Introduction}

A subpopulation of hippocampal pyramidal cells, the place cells, respond to spatial stimuli $^{1-5}$. These cells have been proposed to play a role in spatial recognition and spatial learning: specific areas of the hippocampus respond to different sectors of the environment once animals are acquainted with the place ${ }^{6,7}$. Hippocampal lesions in many species affect spatial recognition and spatial memory ${ }^{3,8-10}$. Further, the administration of a variety of drugs that cause reversible inhibition of hippocampal activity hinders not only learning that relies on distant spatial cues ${ }^{11}$ but also other forms of memory that depend on spatial cues close to the animal ${ }^{12,13}$. Hippocampal place cell activity is related to that of entorhinal grid cells ${ }^{4}$. These two mesial temporal lobe regions have strong bidirectional interactions, which explains their role in spatial and other forms of memory, as well as their relation with the amygdala ${ }^{12}$.

In mesial temporal sclerosis (MTS) there is damage to hippocampal pyramidal cells ${ }^{14,15}$. Alterations of spatial orientation, spatial memory ${ }^{14,16}$ as well as of memory as a whole have been described in these patients after large hippocampal resections carried out to treat MTS (see references in $10,13,17)$. Today, the most widely used resection procedures are temporal anterior lobectomy (TAL) and selective amygdalohippocampectomy (SAH). TAL involves a cortical incision in the mesial temporal gyrus approximately $4.5 \mathrm{~cm}$ behind the temporal pole of the dominant hemisphere and $6 \mathrm{~cm}$ behind it in the non-dominant hemisphere $^{3}$. SAH was developed in more recent years, in order to minimize cognitive impairment. This keeps neocortical resection to a minimum, and consists of removal by aspiration of the anterior $2 \mathrm{~cm}$ of the superior temporal gyrus, the temporal horn, amygdala, uncus and 1 to $2 \mathrm{~cm}$ of hippocampus ${ }^{14,18}$. SAH is usually unilateral. Both procedures are similarly effective for the treatment of seizures (about $80 \%$ of abolition over a period of 8 years), but $\mathrm{SAH}$ is superior from the point of view of minimizing cognitive impairments ${ }^{19}$.

The objective of this study was to develop a test to evaluate spatial orientation memory in patients with Alzheimer's disease, who are known to have bilateral damage to their hippocampus, amygdala and entorhinal cortex, among other brain areas ${ }^{20,21}$, and in patients with unilateral MTS with and without unilateral SAH. The lesions typical of AD appear in stages ${ }^{21}$, but some are seen even at the mild initial periods ${ }^{22}$, which points to the importance of an early diagnosis. Mild Alzheimer's disease is characterized by restricted lesions mostly in the temporal tip, particularly entorhinal cortex and hippocampus ${ }^{21}$.

\section{Method}

\section{Two studies were carried out}

In Experiment 1, 10 patients with initial and mild Alzheimer Disease (AD) were selected and chosen among the components of the Criciúma Alzheimer Group and "São Vicente de Paula" Home, with ages between 65 and 80 years ( 7 women, 3 men; mean age, 71.6 years; mean years of schooling, 2.0). Only AD patients were included whose scores in the 'Mini-Mental State Examination' (MMSE) of at least $21^{23}$, whose score in the 'Clock Drawing Task' ${ }^{24}$ was above 2, and whose classification in the Clinical Dementia Rating (CDR) ${ }^{18,25}$ was equal to 1 . These patients had a preservation of comprehension and other functions, and were able 
to understand the spatial orientation memory test. The controls were 10 healthy volunteers matched to the AD patients by sex (7 women, 3 men), age (mean 72.8 years) and schooling (mean 3.1 years), and with no history of neurological disease. All age and schooling differences between groups were not significant at a $\mathrm{p}=0.1$ level in $t$ tests.

In Experiment 2, we studied 43 patients of the Epilepsy Surgery Programme (ESP) of the Sao Lucas Hospital of PUCRS, and 23 control subjects. Twenty-three of the patients had refractory epilepsy secondary to unilateral MTS (15 on the right side, 8 on the left side) and were candidates for surgery for the epilepsy treatment, and 20 patients had once suffered from MTS and had been submitted to SAH between 8 and 12 months before (10 on the right side, 10 on the left side). Diagnosis of the MTS was both electroencephalographic (EEG) and by magnetic resonance imaging (MRI) in all cases. The sample was taken from patients selected from April 2004 to December, 2004 for the Epilepsy Surgery Programme. In the control group sample, 23 healthy volunteers were included, selected so as to correspond as close as possible to the sex, age and level of schooling of both the MTS and the SAH individuals; the controls were also selected by having no record of neurological disease. In the control group there were 12 women and $11 \mathrm{men}$; in the MTS group there were 13 men and 10 women, and in the SAH group there were 13 men and 7 women; differences among groups in gender predominance were not significant at a $\mathrm{p}=$ 0.1 level. Mean age was 38.5 years in controls, 38.3 years in the MTS group and 35.1 years in the $\mathrm{SAH}$ group. Mean years of schooling was 3.9, 3.6 and 3.8 respectively. Differences in these measures between groups were not significant at a $\mathrm{p}=0.1$ level in a Duncan multiple range test. The SAH patients studied had been operated at least 8 months before behavioural testing.
Both in Experiment 1 and Experiment 2, controls were volunteers from the hospital employee staff and from the family environment of the patients. Their participation was obtained by explaining to them the nature and purpose of the tests, and its potential contribution to the study of cognitive aspects of mental health, and just asking them if they volunteered. Among controls, groups of similar age and similar number of years of schooling to the corresponding patients examined were allotted to Experiments 1 and 2.

All individuals received the same instructions for the test, and the same test was used in both Experiments. The patient was placed on a chair in the middle of a $9.45 \times 7.33 \mathrm{~m}$ room where different $60 \times 60 \mathrm{~cm}$ yellow figures hung from the center of the clear grey walls: a cylinder from the wall in front, a square from the left wall, a ball from the right wall, and a triangle from the wall to the back of the subject (Figure 1). The door was $0.80 \mathrm{x}$ $2.00 \mathrm{~m}$, at the left front corner, and was kept closed during the trials. An observer standing behind the chair accompanied the subject. The duration of each trial was 3 min of adaptation followed by $3 \mathrm{~min}$ for the trial itself.

In the first trial, the subject was instructed to go to the cylinder, then to the square, then to the ball and finally to the triangle (4 questions). In the second trial, the subjects were required to repeat this, but blindfolded; all figures except the cylinder were removed and once the subjects reached the cylinder they were required to say what figures should be at the left, at the right and at the back walls (4 questions). In the third trial, all figures were withdrawn and the subjects, again blindfolded, were instructed first to go to the front, right, left and back (4 questions), and then to go to the former positions occupied by the cylinder, the ball, the square and the triangle (another 4 questions). Thus, maximum performance $(100 \%)$ consisted of 16 correct responses. 
The memory test used here is an unusual instrument for humans, and is derived from animal experiments designed to measure spatial orientation memory ${ }^{1,2,11}$. It involves both spatial memory (to remember the position of the pictures position in the room) and spatial orientation (to guide themselves within the room, from centre to right, left and back).

Statistical analysis was by a Student's $t$ test in the first study (AD), in which there were only two groups, and by a Duncan multiple range test in the second study (MTS and $\mathrm{SAH})$, which involved several groups.

The project was approved by the Commission of Ethics in Health of the Pontifical Catholic University of Rio Grande do Sul
(PUCRS). All participants were informed about the aims of the research, and the individuals to be studied signed a Term of Consent.

\section{Results}

Experiment 1. In the first study, performance in the spatial memory test was evaluated in 10 patients with $\mathrm{AD}$ and 10 healthy volunteers. Individual ages, schooling years and performance are listed in Table I. The results of each group and the statistics are shown in Table III. The difference in performance of correct responses between the two groups was significant to the level of $\mathrm{p}<$

Table I

Age, years of schooling and performance in the spatial memory test of control individuals and patients in Experiment 1 .

\begin{tabular}{llccc}
$\begin{array}{l}\text { Controls } \\
\text { Number }\end{array}$ & Age & Gender & Years of schooling & Test performance \% \\
\hline 01 & 73 & $\mathrm{~F}$ & 9 & 81.25 \\
02 & 65 & $\mathrm{~F}$ & 4 & 100.00 \\
03 & 80 & $\mathrm{~F}$ & 1 & 93.75 \\
04 & 70 & $\mathrm{M}$ & 3 & 93.75 \\
05 & 72 & $\mathrm{~F}$ & 1 & 93.75 \\
06 & 77 & $\mathrm{~F}$ & 2 & 100.00 \\
07 & 75 & $\mathrm{M}$ & 2 & 62.5 \\
08 & 73 & $\mathrm{~F}$ & 1 & 87.5 \\
09 & 73 & $\mathrm{~F}$ & 5 & 87.5 \\
10 & 70 & & 2 & 93.75 \\
\hline Means & 72.8 & & 3.1 & 89.4 \\
Alzheimer patients & & $\mathrm{F}$ & & \\
\hline 01 & 78 & $\mathrm{~F}$ & 12 & 81.25 \\
02 & 73 & $\mathrm{~F}$ & 5 & 50.00 \\
03 & 80 & $\mathrm{M}$ & 1 & 37.50 \\
04 & 70 & $\mathrm{~F}$ & 4 & 37.50 \\
05 & 71 & $\mathrm{M}$ & 1 & 87.50 \\
06 & 70 & $\mathrm{M}$ & 4 & 62.50 \\
07 & 70 & $\mathrm{~F}$ & 3 & 37.50 \\
08 & 69 & $\mathrm{~F}$ & 1 & 37.50 \\
09 & 70 & $\mathrm{~F}$ & 6 & 37.50 \\
10 & 65 & & 1 & 12.50 \\
\hline Means & 72.6 & & 3.8 & 48.1 \\
\hline
\end{tabular}


Table II

Age, years of schooling and performance in the spatial memory test of control individuals and patients in Experiment 2.

\begin{tabular}{llccc}
$\begin{array}{l}\text { Controls } \\
\text { Number }\end{array}$ & Age & Gender & Years of schooling & Test performance \% \\
\hline 01 & 42 & F & 5 & 93.75 \\
02 & 31 & M & 12 & 93.75 \\
03 & 32 & M & 3 & 100.00 \\
04 & 36 & M & 3 & 93.75 \\
05 & 31 & F & 4 & 93.75 \\
06 & 32 & F & 3 & 100.00 \\
07 & 33 & M & 7 & 87.50 \\
08 & 44 & M & 4 & 75.00 \\
09 & 25 & M & 1 & 93.75 \\
10 & 28 & F & 6 & 93.75 \\
11 & 35 & F & 1 & 100.00 \\
12 & 51 & M & 3 & 58.75 \\
13 & 34 & F & 4 & 100.000 \\
14 & 48 & M & 12 & 100.00 \\
16 & 35 & M & 1 & 56.25 \\
17 & 48 & M & 4 & 75.00 \\
18 & 41 & M & 4 & 100.00 \\
19 & 42 & F & 4 & 100.00 \\
20 & 26 & F & 4 & 90.00 \\
21 & 32 & F & 5 &
\end{tabular}

MTS patients

\begin{tabular}{llccc} 
Number & Age & Gender & Years of schooling & Test performance \% \\
\hline 01 & 41 & F & 4 & 62.5 \\
02 & 31 & M & 12 & 100.00 \\
03 & 32 & M & 3 & 81.25 \\
04 & 36 & M & 3 & 100.00 \\
05 & 31 & F & 4 & 100.00 \\
06 & 42 & M & 3 & 100.00 \\
07 & 32 & F & 6 & 100.00 \\
08 & 44 & M & 4 & 62.50 \\
09 & 35 & M & 1 & 100.00 \\
10 & 38 & F & 6 & 87.50 \\
11 & 35 & M & 1 & 100.00 \\
12 & 50 & F & 3 & 100.00 \\
13 & 34 & M & 6 & 100.00 \\
14 & 47 & F & 12 & 93.75 \\
15 & 35 & M & 5 & 100.00 \\
16 & 47 & M & 8 & 100.00 \\
17 & 48 & F & 4 & 100.00 \\
18 & 41 & M & 4 & 100.00 \\
19 & 40 & F & 8 & 87.50 \\
20 & 26 & F & 4 & 75.50 \\
21 & 32 & F & 4 & 91.00 \\
22 & 45 & & 4 & \\
23 & 38 & & 4.8 & \\
\hline Means & 41.4 & & &
\end{tabular}


Table II (continue)

SAH patients

\begin{tabular}{llccr} 
Number & Age & Gender & Years of schooling & Test performance \% \\
\hline 01 & 40 & M & 7 & 93.75 \\
02 & 43 & M & 12 & 100.00 \\
03 & 28 & M & 1 & 93.75 \\
04 & 28 & F & 3 & 100.00 \\
05 & 30 & M & 1 & 100.00 \\
06 & 30 & M & 3 & 87.50 \\
07 & 38 & M & 7 & 100.00 \\
08 & 40 & M & 3 & 100.00 \\
09 & 38 & M & 1 & 100.00 \\
10 & 27 & M & 5 & 100.00 \\
11 & 43 & M & 1 & 100.00 \\
12 & 34 & F & 3 & 100.00 \\
13 & 38 & F & 1 & 93.75 \\
14 & 32 & F & 4 & 87.50 \\
15 & 33 & F & 3 & 100.00 \\
16 & 38 & M & 1 & 100.00 \\
17 & 43 & F & 5 & 100.00 \\
18 & 33 & M & 7 & 100.00 \\
19 & 32 & M & 5 & 100.00 \\
20 & 44 & & 4 & 97.5 \\
\hline Means & 35.6 & & 3.8 &
\end{tabular}

0.001 in a $t$ test. Thus, there was a marked deficit in performance in the Alzheimer group relative to controls. This may be taken as a validation of the test.

Experiment 2. In the second study, 23 unoperated patients with unilateral MTS (15 on the right side, 8 on the left side), 20 MTS patients submitted to unilateral SAH (10 on the right and 10 on the left side), and 23 control subjects were studied. The individual age, years of schooling and performance in the test of the controls, MTS and SAH groups are listed in Table III. The group results and statistics are shown in Table III. As can be seen, differences between MTS, SAH and control groups were not significant in a Duncan multiple range test at a $\mathrm{p}=$ 0.05 level. Therefore, no effects of either MTS or the SAH could be detected. In addition, no influences of the side of the lesion or of the surgery could be detected. Following the tests of Experiment 2, patients in the three groups were informally asked how they were feeling lately. Controls regularly said that they felt nothing in particular, neither better nor worse than usual. MTS patients often said that they expected that surgery would make them feel better (they were all inscribed, as mentioned under Methods, in the Surgery program of the hospital). In sharp contrast, all SAH patients declared that the surgery had enabled them to "recover lost time", and/or to be "tranquil", to feel better and happier because of the lack of epileptic crises, and/or to have improved their interaction with other people. Some were more emphatic than others, but none was indifferent about the beneficial effects of the surgery they had been submitted to.

Importantly, no difference in performance of correct responses between the control group of this study and that of the preceding one was detected. Since there was a large age difference between those two 
populations, this means that the present observations appear not to discriminate between the respective age of the two control populations (mean 72.6, range $65-80$ in Experiment 1; mean 38.5, range $25-51$ in Experiment 2). No difference in performance between men and women was detected in any of the groups in Table I and III. The number of years of schooling was not significantly different across groups in any of these two tables. No significant correlation between years of schooling and performance in the test was detected in any of these groups ( $\mathrm{p}>0.1 \%$ in Pearson tests).

Table III

Percentage of correct responses in control subjects and in patients with mild or initial Alzheimer's disease.

\begin{tabular}{llc} 
Group & N & Mean \pm SD correct responses \\
\hline Controls & 10 & $89.4 \pm 22.8$ \\
Alzheimer's patients & 10 & $48.1 \pm 11.0 *$
\end{tabular}

*Significant difference from controls at $\mathrm{p}<0.001$ level in a $t$ test.

Table IV

Percentage of correct responses in control subjects and in patients with unilateral mesial temporal lobe sclerosis, either unoperated (MTS) or submitted to selective unilateral amygdalo-hippocampectomy at least 6 months before.

\begin{tabular}{lcc} 
Group & $\mathrm{N}$ & Mean \pm SD correct responses \\
\hline Controls & 23 & $90.2 \pm 14.8$ \\
MTS total & 23 & $91.2 \pm 12.5$ \\
MTS right side & 15 & $92.1 \pm 11.2$ \\
MTS left side & 8 & $91.4 \pm 13.7$ \\
SAH total & 20 & $97.5 \pm 4.2$ \\
SAH right side & 10 & $97.5 \pm 4.4$ \\
SAH left side & 10 & $97.4 \pm 4.3$ \\
\hline
\end{tabular}

All differences between means, not significant at a $\mathrm{p}=0.05$ level in a Duncan multiple range test. Difference between the control group of this experiment and that of Table 1 is not significant at a $\mathrm{p}=0.1$ level in a $t$ test .

\section{Discussion}

The results show that the test described here permits a reasonable exploration of spatial orientation and spatial learning in subjects between 25 and 80 years of age, and with very low (1 year) to relatively high (12 years) levels of schooling. The test detects important differences between AD patients and age, gender and schoolingmatched controls. This ratifies observations in the literature on the early disruption of spatial orientation in the course of $\mathrm{AD}^{24,26}$.
The patients with $\mathrm{AD}$ presented a much lower average of correct responses $(48.1 \%)$ than the controls $(89.4 \%)(\mathrm{p}<0.001)$. The data are coherent both with the incidence of lesions in the hippocampus and related areas in $\mathrm{AD}^{20,21}$, and with the proposed role of these structures in spatial cognitive variables (see above).

The test failed to detect differences in performance between MTS patients, SAH patients and their controls. Therefore, whatever deficits in spatial cognition there may be in these populations must be considered 
to be very small relative those seen in AD patients ${ }^{19}$.

As said above, we were left with the clinical impression of a general improvement of mood in the SAH group, although no specific measurement of this was made. The apparent improvement of mood could account for the slightly (6\%), though not significantly $(\mathrm{p}>0.05)$, improved performance in of SAH patients relative to both MTS patients and controls. There are numerous descriptions of improved performance in memory tests secondary to an improvement of mood ${ }^{12,13}$. Unilateral ablation of the amygdala may induce a general sense of well-being, perhaps related to what has been described as placidity in animals or humans ${ }^{27,28}$. In any case, the present test was unable to detect spatial orientation memory deficits in MTS or SAH patients.

In conclusion. A new test to evaluate spatial orientation and spatial memory was presented. The test functions well in subjects between the ages of 25 and 80, and with low or high schooling levels. It detects spatial memory deficits in D patients, but not in patients with MTS or SAH.

\section{References}

1. O'Keefe J, Dostrovsky J. The hippocampus as a spatial map. Preliminary evidence from unit activity in the freely-moving rat. Brain Res 1971; 34: 171-175.

2. O'Keefe JA. Place units in the hippocampus of the freely moving rat. Exp Neurol 1979; 51: 78-109.

3. Moser E, Paulsen O. New excitement in cognitive space: between place cells and spatial memory. Neurobiol Behav 2001; 11: 745-751.

4. O'Keefe J, Burgess N. Dual phase and rate coding in Hippocampal place cells: theoretical significance and relationship to entorhinal grid cells. Hippocampus 2005; 853866.
5. Burgess N, Cacucci F, Lever C, O'Keefe J. Characterizing multiple independent behavioral correlates of cell firing in freely moving animals. Hippocampus 2005; 15: 149153.

6. Wilson MA, McNaughton BL. Reactivation of hippocampal ensemble memories during sleep. Science 1994; 265: 676-679.

7. Nakazawa K, McHugh TJ, Wilson MA, Tonegawa S. NMDA receptors, place cells and hippocampal spatial memory. Nature Rev Neurosci 2004; 5: 361-372.

8. Hollup AS, Molden S., Donnett JG et al. Place fields of rat hippocampal pyramidal cells and spatial learning in the watermaze. Eur J Neurosci 2001; 13: 1197-1208.

9. Hamilton DA, Driscoll I, Sutherland RJ. Human place learning in a virtual Morris water task: some important constraints on the flexibility of place navigation. Behav Brain Res 2002; 129: 159-170.

10. Corkin S. What's new with the amnesic patient H.M.? Nature Neurosci 2002; 3: 153-160.

11. Morris RG, Anderson E, Lynch G et al. Selective impairment of learning and blockade of long-term potentiation by an N-methyl-D-aspartate receptor antagonist, AP5. Nature 1986; 319, 774-776.

12. Izquierdo I, Medina JH. Memory formation: the sequence of biochemical events in the hippocampus and its connection to activity in other brain structures. Neurobiol Learn Mem 1997; 68: 285-316.

13. Izquierdo I, McGaugh JL. Behavioural pharmacology and its contribution to the molecular basis of memory consolidation. Behav Pharmacol 2000; 12: 517-534.

14. Costa JC. Síndromes Epiléticas. In Nunes ML, Marrone $\mathrm{CH}$. Semiologia Neurológica. Porto Alegre: Edipucrs, 2000: 373-385.

15. Alessio A, Damasceno BP, Camargo CH et al. Differences in memory performance and other clinical characteristics in patients with mesial temporal lobe epilepsy with and without hippocampal atrophy. Epilepsy Behav 2004; 5: 22-27.

16. Stepankova K, Fenton A., Pastalkova A. et al. Object-location impairment in patients with thermal lesions to the right or left hippocampus. Neuropsychologia 2004; 42: 1017-1028.

17. Steinvorth S, Levine B, Corkin S. Medial temporal lobe structures are needed to re-experience remote autobiographical memories: evidence from H.M. and W.R. Neuropsychologia 2005; 43: 479-496.

18. Caramelli P, Nitrini R. Como avaliar de forma breve e objetiva o estado mental de um paciente? Rev Assoc Med Brasil 2000; 46: 301-304. 
19. Incisa-della-Rocchetta A, Samson S, Ehrle N et al. Memory for visuospatial location following selective hippocampal sclerosis: the use of different coordinate systems. Neuropsychology 2004; 18: 15-28.

20. Arriagada PV, Marzloff K, Hyman BT. Distribution of Alzheimer-type pathologic changes in nondemented elderly individuals matches the pattern in Alzheimer's disease. Neurology 1992; 42: 1681-1688.

21. Braak H, Braak E. Evolution of neuronal changes in the course of Alzheimer's disease. J Neural Transm Suppl 1998; 53(Suppl): 127-140.

22. Soltys K, Rolkova G, Vechterova L et al.. First insert of tau protein is present in all stages of tau pathology in Alzheimer's disease. Neuroreport 2005; 42: 1677-1681.

23. Folstein MF, Folstein SE, McHugh PR. Mini-Mental State. A practical method for grading the cognitive state of patients for the clinicians. J Psychiat Res 1975: 189-198.

24. Sunderland T, Hill J.L, Mellow AM. Clock drawing in Alzheimer disease. J Am Geriatric Soc 1989; 37: 725-729.
25. Morris JC. The clinical dementia rating (CDR). Neurolog 1993; 43: 2412-2414.

26. Nitrini R, Almeida OP. Demências - Quadro Clínico e Critérios Diagnósticos. In: Demência. Rio de Janeiro: Fundo Editorial BYK, 1995: 90-99.

27. Abrahams S, Morris RG, Polkey CE et al. Hippocampal involvement in spatial and working memory: a structural MRI analysis of patients with unilateral mesial temporal lobe sclerosis. Brain Cogn 1999; 41: 39-65.

28. Carroll BT, Goforth HW, Raimonde LA. Partial Kluver-Bucy syndrome: two cases. CNS Spectr 2001; 6: 329-332.

Address for correspondence: Lisiane Tuon and Iván Izquierdo Centro de Memoria, I.P.B.

Av. Ipiranga, 6690, $2^{\circ}$. Andar (90610-000) Porto Alegre, RS, Brasil

E-mail: ivan.izquierdo@pucrs.br 